\title{
MORAL HAZARD AND \\ OPTIMAL COMMODITY TAXATION
}

\author{
Richard ARNOTT \\ Department of Economics, Queen's University, Kingston, Ontario K7L 3N6, Canada
}

Joseph E. STIGLITZ*

Department of Economics, Princeton University, Princeton, NJ 08544, USA

Received November 1983, revised version received June 1985

This paper demonstrates that in an economy with moral hazard and more than one commodity, competitive equilibrium is not constrained-efficient. To correct the market failure, differential commodity taxation is necessary. A general optimal tax formula is derived, and special cases of it discussed.

\section{Introduction}

There has been increasing awareness over the past fifteen years of the importance and pervasiveness of problems of moral hazard. Risk-averse individuals purchase insurance which affects their incentives to undertake accident-avoidance activities. With perfect (costless) information, insurance contracts would specify the actions to be undertaken and provide complete insurance. With costly information, however, insurance contracts provide only partial insurance, balancing at the margin the loss in reduced incentives from providing more insurance and the gain from risk-sharing. Moral hazard problems arise not only in insurance markets, but also in labor, product, and capital markets, in all of which elements of implicit or explicit insurance are prevalent in contractual relations.

In this paper we establish that, with more than one consumer good and costless government intervention, competitive equilibrium is almost always (constrained) inefficient when moral hazard is present; and to correct the market failure, differential commodity taxation is necessary.

The rationale for this result is as follows. Consider the extreme moral

${ }^{*}$ We would like to thank the National Science Foundation and the Social Sciences and Humanities Research Council of Canada for financial support, Jim Gaisford for expositional criticism, and seminar participants at Queen's, Stanford, Yale, Aarhus, and Tel-Aviv Universilies, and M.I.T. and the Norwegian School of Economics for useful comments. 
hazard situation, in which the insurer can observe only the outcome of an accident and has no information on either the underlying state of nature or the precaution taken by the individual to prevent the accident. In this case, the insurer can do no better than to provide insurance against the accident per se (i.e. he cannot make the payout contingent on either the insured's actions or the state of nature). As a result, the individual will normally take less care than is socially desirable. This in itself does not imply constrained inefficiency; all it says is that the unobservability of accident-prevention activities entails a welfare cost. Now consider the effect in the economy with moral hazard of subsidizing those goods that are complementary to accidentavoidance activities, and taxing those goods that are substitutable for them. The individual will undertake more accident-prevention activity, which will reduce the welfare cost associated with being insufficiently careful. However, such commodity taxation, by causing prices to diverge from marginal costs, introduces a second welfare cost. Constrained efficiency obtains when the sum of the two welfare costs is minimized, and we establish that this does involve differential commodity taxation. ${ }^{1}$ Put another way: When insurance is provided in the presence of moral hazard, the insured faces the marginal social cost of accident prevention, but since he is insured, his marginal private benefit is typically less than marginal social benefit. As a result, he will take less than the socially optimal amount of care. This can be corrected by lowering the private cost of accident prevention.

The rationale for differential commodity taxation here is different from that in the conventional optimal tax literature [e.g. Atkinson and Stiglitz (1980)]. There, the tax authorities would like to tax individuals according to say ability, but this is presumed to be unobservable and as a result the tax authorities must tax observable items, which include commodities, on the basis of their correlation with ability. If individuals were identical, it would be efficient to impose lump-sum taxation; differential commodity taxation would be harmful. Here, however, even with identical individuals so that lump-sum taxation is possible, one will want to impose differential commodity taxation.

We organize our discussion as follows. Section 2 presents the general model, while section 3 examines a couple of special.cases. In section 4 we discuss a few of the possible policy applications of our analysis. And sections 5 and 6 give concluding comments.

\footnotetext{
${ }^{1}$ It appears to have been the conventional wisdom that moral hazard does not cause constrained inefficiency. This belief is based on the results of Pauly (1974), Stiglitz (1974), Helpman and Laffont (1975), Marshall (1976), and Shavell (1979a, 1979b) among others, all of which assume that there is a single consumer good, a linear production technology, and observability of an individual's total insurance purchases. In Arnott and Stiglitz (1984b) we showed that constrained efficiency obtains under these assumptions, but not when any of them is relaxed.
} 


\section{The general model}

We start by considering a general formulation of the optimal tax problem with moral hazard. This will give insight into the structure of the problem. Unfortunately, the first-order conditions (as in the conventional optimal commodity tax problem), though interpretable, are sufficiently complex that they provide little guidance concerning the optimal tax rates on the various goods. As a consequence, in the next section we treat two special cases, both of which focus on a different determinant of the optimal tax structure.

We assume that there is a single representative risk-averse individual in the economy for whom there are $I$ possible outcomes indexed by $i^{2,3}$ Outcomes are differentiated on the basis of which of a variety of kinds of accidents befall the individual, and the damage associated with each of the accidents. The outcome may affect the individual either directly (giving him pain or pleasure and affecting his tastes) or via his gross (of insurance premium and payout) income.

For simplicity, in this paper we assume that an individual's total purchases of a commodity are unobservable; this implies that only linear taxation is feasible, and that the insurer cannot write his insurance contingent on an individual's purchases. Thus, the insurer can do no better than choose the net payout (payout minus premium) for each outcome, some of which may be negative. We will, however, assume throughout that the government and the market can observe the total quantity of insurance which an individual purchases. ${ }^{4}$ To simplify the analysis, we treat a linear production technology, and measure produced goods in such a way that all producer prices are unity.

A doubling of all consumer prices and net (of net payout) incomes in this economy has no effect. We therefore require another normalization. There is no obviously preferable one. We shall employ different normalizations in different parts of the paper. In this section, we normalize on the basis of the individual's net income if no accident befalls him.

We distinguish between goods $\left(c^{k}\right)$ which can be taxed and activities $\left(e^{j}\right)$ which cannot. ${ }^{5}$ We let $i$ denote the outcome $(i=0$ corresponds to no accident), ${ }^{6} x_{i}$ the individual's net insurance payout with outcomes $i, y_{i}$ gross

\footnotetext{
${ }^{2}$ Thus we rule out problems associated with adverse selection.

${ }^{3}$ Alternatively, one may interpret the model as applying to an economy with a large number of ex ante identical individuals whose accident outcomes are statistically independent.

${ }^{4}$ Some problems which arise when this is not so are treated at length in Arnott and Stiglitz (1984b).

${ }^{5}$ The analysis can be extended to the case where there are goods which cannot be taxed

${ }^{6}$ Our notation admits multiple accident outcomes; thus if there were two types of accidents, fire and automobile, then we might let $i=1$ denote a fire, $i=2$ an automobile accident, and $i=3$ both. Our notation also admits accidents of varying sizes, though for simplicity, we have limited ourselves to a finite number of outcomes.
} 
income $\left(y_{0}=1\right)$ and

$$
z_{i}=y_{i}+x_{i}
$$

the individual's net of insurance income with outcome $i$.

Some goods are purchased before the accident occurs, and some after. Commodities (and their prices) purchased prior to the accident are denoted with a caret while commodities purchased after are denoted with a bar. Clearly, only purchases prior to the accident can affect the probability of the accident. ${ }^{7}$ For simplicity, we shall assume all non-taxable activities occur prior to the accident. ${ }^{8}$ Thus, $\pi_{i}$, the probability of outcome $i$, is (where $e$ and $\hat{c}$ are column vectors)

$$
\pi_{i}=p_{i}(\hat{c}, e)
$$

while utility with outcome $i$ is

$$
u_{i}=u_{i}\left(c_{i}, e\right)
$$

where $\partial u_{i} / \partial c_{i}^{k}>0, \partial^{2} u_{i} / \partial\left(c_{i}^{k}\right)^{2}<0$, and $\partial u_{i} / \partial e^{j}<0$ and $c_{i}$ (with no bar or caret) denotes the column vector of both pre- and post-outcomc goods with outcome $i$. Note that we allow tastes to depend on the outcome. Expected utility is

$$
\mathrm{E} U=\sum_{i} p_{i}(\hat{c}, e) u_{i}\left(c_{i}, e\right)
$$

With outcome $i$, the individual's budget constraint is

$$
z_{i}=q c_{i}
$$

where $q$ is the row vector of consumer prices.

\subsection{The consumers' problem}

The individual's budget allocation can be described as a two-stage process. Prior to the realization of the outcome he purchases the vector $\hat{c}$. After realization $i$, he therefore has $\bar{z}_{i}=z_{i}-\hat{q} \hat{c}$ to spend. He chooses $\bar{c}_{i}$ to maximize $u_{i}\left(\bar{c}_{i} ; \hat{c}, e\right)$ subject to $\bar{q} \bar{c}_{i}=\bar{z}_{i}$. We denote the solution to this by the (outcomecontingent) quasi-indirect utility function $v_{i}\left(\bar{z}_{i}, \bar{q} ; \hat{c}, e\right)$. He then chooses $e$ and

${ }^{7}$ This formulation here obviously involves collapsing a multi-period problem into a singleperiod analysis; for our purposes, there is no loss in doing so.

${ }^{8}$ If there are untaxed activities during the post-accident period, we can incorporate their effects into a derived (indirect) utility function. 
$\hat{c}$ to maximize

$$
\begin{aligned}
& \sum_{i} p_{i}(\hat{c}, e) v_{i}\left(\bar{z}_{i}, \bar{q} ; \hat{c}, e\right) \\
& \text { s.t. } \\
& \bar{z}_{i}=z_{i}-\hat{q} \hat{c} .
\end{aligned}
$$

We assume here and throughout the rest of this paper that there is a unique, interior maximum to each of the maximization problems considered. This is admittedly a very strong assumption; a unique, interior optimum is not guaranteed in the conventional optimal commodity taxation problem, and moral hazard may cause even the consumer's maximization problem to be non-convex [see Arnott and Stiglitz (1984a)].

The first-order conditions to (6) are

$$
e^{j}:\left(\sum_{i} \frac{\partial p_{i}}{\partial e^{j}} v_{i}+\sum_{i} p_{i} \frac{\partial v_{i}}{\partial e^{j}}\right)=0
$$

and

$$
\hat{c}^{k}: \sum_{i} \frac{\partial p_{i}}{\partial \hat{c}^{k}} v_{i}+\sum_{i} p_{i}\left\{\frac{\partial v_{i}}{\partial \hat{c}^{k}}-\hat{q}^{k} \frac{\partial v_{i}}{\partial \bar{z}_{i}}\right\}=0
$$

In (7), $\sum_{i}\left(\partial p_{i} / \partial e^{j}\right) v_{i}$ is the expected marginal benefit in utiles from a unit increase in effort $j$, while $\sum_{i} p_{i}\left(\partial v_{i} / \partial e^{j}\right)$ is the corresponding marginal cost. Eq. (8) has an analogous interpretation. ${ }^{9}$ We can therefore obtain commodity demand and effort supply functions $e=e(q, z), \hat{c}=\hat{c}(q, z)$ and $\bar{c}_{i}=\bar{c}_{i}(q, z)$. Substituting these equations into (4) gives:

$$
\mathrm{E} U=\sum_{i} \pi_{i}(q, z) V_{i}(q, z)
$$

Define $\alpha_{i} \equiv \partial v_{i} / \partial \bar{z}_{i}=\partial v_{i} / \partial z_{i}$ for all $i$. We note for future reference that ${ }^{10,11}$

$$
\frac{\partial \mathrm{E} U}{\partial x_{i}}=\frac{\partial \mathrm{E} U}{\partial z_{i}}=\pi_{i} \alpha_{i}
$$

${ }^{9}$ Note that this formulation of the consumer's problem assumes that if an individuil purchisw a good, he will use it. We retain this assumption in the text. But with this assumption, the optimal consumer price of a good can be negative. This can occur when the individual is better off if the accident occurs; to induce him to take care it is necessary to set the price of accidentprevention goods negative.

In appendix B we adopt the alternative assumption that an individual need not use a good he purchases. If this alternative assumption were used in the text, the planner's problem would be augmented by the constraints $q>0$.

${ }^{10}$ From (6) $\partial \mathrm{E} U / \partial x_{i}=\partial \mathrm{E} U / \partial \bar{z}_{i}=\alpha_{i} p_{i}=\alpha_{i} \pi_{i}$.

${ }^{11}$ From (6), $\partial \mathrm{E} U / \partial \hat{q}^{k}=-\sum_{i} p_{i} \hat{c}^{k}\left(\partial v_{i} / \partial z_{i}\right)=-\sum_{i} \pi_{i} \hat{c}_{i}^{k} \alpha_{i}$ and $\partial \mathrm{E} U / \partial \bar{q}^{k}=\sum_{i} p_{i}\left(\partial v_{i} / \partial \bar{q}^{k}\right)$. Also, $\partial v_{i} / \partial \bar{q}^{k}=-\bar{c}_{i}^{k} \alpha_{i}$. Thus $\partial \mathrm{E} U / \partial \bar{q}^{k}=-\sum_{i} \pi_{i} \bar{c}_{i}^{k} \alpha_{i}$. 
and

$$
\frac{\partial \mathrm{E} U}{\partial q^{k}}=-\sum_{i} c_{i}^{k} \pi_{i} \alpha_{i} .
$$

\subsection{The social planner's problem}

The social planner is assumed not to be able to control consumption or accident-prevention activities directly, but only indirectly - he can control the insurance vector, $x$, and the prices of commodities, $q$.

The economy-wide resource constraint facing the planner is

$$
\sum_{i} \pi_{i}\left(1 \cdot c_{i}-y_{i}\right)=0
$$

where $I$ is the unit row vector. Using the individual's budget constraint, $z_{i}=q c_{i}$, we may write (12) alternatively as

$$
\sum_{i} \pi_{i} x_{i}=\sum_{i} \pi_{i}(q-1) c_{i}
$$

which states that (expected) net insurance payouts must equal (expected) tax revenues.

The planner's problem may then be written as

$$
\max _{q, x} \sum_{i} \pi_{i} V_{i}-\lambda\left(\sum_{i} \pi_{i}\left(x_{i}-(q-1) c_{i}\right)\right)
$$

where $\lambda$ is the Lagrange multiplier on (12). Define

$$
s_{i} \equiv x_{i}-(q-1) c_{i}
$$

to be the net subsidy with outcome $i$. Then the planner's problem can be written more compactly as

$$
\max _{q, x} \mathscr{L}=\mathrm{E} U-\lambda \sum_{i} \pi_{i} s_{i}
$$

It turns out that the relevant 'compensated' derivative in the optimal tax formula entails compensation such that, after the change, the individual is able to purchase his pre-change, outcome-contingent bundles of goods and no more, which preserves expected utility; ${ }^{12}$ thus, where a subscript $\theta$

$$
12 \quad\left(\frac{\partial \mathrm{E} U}{\partial q^{k}}\right)_{\theta}=\frac{\partial \mathrm{E} U}{\partial q^{k}}+\sum_{i} c_{i}^{k} \frac{\partial \mathrm{E} U}{\partial x_{i}}=-\sum_{i} \alpha_{i} \pi_{i} c_{i}^{k}+\sum_{i} c_{i}^{k} \alpha_{i} \pi_{i}=0
$$


denotes such compensation:

$$
\left(\frac{\partial c_{i}^{k}}{\partial q^{\tilde{k}}}\right)_{\theta}=\frac{\partial c_{i}^{k}}{\partial q^{\tilde{k}}}+\sum_{m} c_{m}^{\bar{k}} \frac{\partial c_{i}^{k}}{\partial x_{m}}
$$

and

$$
\left(\frac{\partial \pi_{i}}{\partial q^{\bar{k}}}\right)_{\theta}=\frac{\partial \pi_{i}}{\partial q^{\bar{k}}}+\sum_{m} c_{m}^{k} \frac{\partial \pi_{i}}{\partial x_{m}}
$$

After some algebraic manipulation, which is given in appendix A, we obtain:

$$
\sum_{i} s_{i}\left(\frac{\partial \pi_{i}}{\partial q^{\tilde{k}}}\right)_{\theta}=\sum_{i} \sum_{k}\left(q^{k}-1\right)\left(\frac{\partial c_{i}^{k}}{\partial q^{\tilde{k}}}\right)_{\theta} \pi_{i}
$$

and

$$
\sum_{i} s_{i}\left(\frac{\partial \pi_{i}}{\partial q^{\tilde{k}}}\right)_{\theta}=\sum_{i} \sum_{k}\left(q^{k}-1\right)\left(\frac{\partial c_{i}^{\tilde{k}}}{\partial q^{k}}\right)_{\theta} \pi_{i}
$$

Let $c$ denote a matrix with elements

$$
\left(\begin{array}{ccc}
c_{1}^{1} & c_{2}^{1} & \cdots \\
c_{1}^{2} & & \\
\vdots & &
\end{array}\right)
$$

and define $\left(\partial c / \partial q^{\tilde{k}}\right)_{\theta}$ accordingly; let $\pi$ denote a column vector with elements $\pi_{i}$ and define $\left(\partial \pi_{i} / \partial q^{\widetilde{k}}\right)_{\theta}$ accordingly; and finally let $s$ denote a row vector with elements $s_{i}$. Then (17) may be rewritten as

$$
s\left(\frac{\partial \pi}{\partial q^{\tilde{k}}}\right)_{\theta}=(q-1)\left(\frac{\partial c}{\partial q^{\tilde{k}}}\right)_{\theta} \pi .
$$

Eq. (19) has two intuitively appealing interpretations. First, it states that at the optimum, the change in net government revenues from a compensated unit increase in $q^{\tilde{k}}$ is zero. ${ }^{13}$ Second, it confirms our claim in the introduction that with the optimal set of taxes, the marginal welfare cost associated with consumer prices diverging from producer prices [the RHS of (19)] equals the marginal welfare cost associated with moral hazard (the LHS).

$$
\begin{aligned}
& { }^{13} R=\sum_{i}\left((q-1) c_{i}-x_{i}\right) \pi_{i} \text {, so } \\
& \quad\left(\frac{\partial R}{\partial q^{k}}\right)_{\theta}=\sum_{i}\left(c_{i}^{k}-\frac{\partial x_{i}}{\partial q^{k}}\right)_{\theta} \pi_{i}+\sum_{i}(q-1)\left(\frac{\partial c_{i}}{\partial q^{k}}\right)_{\theta} \pi_{i}-\sum_{i} s_{i}\left(\frac{\partial \pi_{i}}{\partial q^{k}}\right)_{\theta} .
\end{aligned}
$$

The first term is, by the definition of $\theta$, zero. Thus, $\left(\partial R / \partial q^{\bar{k}}\right)_{\theta}=0$ is equivalent to (19). 
Proposition 1. The optimal tax-cum-insurance structure may be characterized in two ways. First, the change in net government revenuc from a 'compensated' unit increase in any tax rate must be zero. Second, for each tax rate, the marginal welfare cost associated with moral hazard must equal that associated with the wedges between consumer and producer prices.

It is straightforward to convert (19) into a simple formula for the optimal tax structure. Define $\Lambda$ to be a matrix with elements $\Lambda_{\bar{k}, k}=\sum_{i}\left(\partial c_{i}^{k} / \partial q^{\bar{k}}\right)_{\theta} \pi_{i}$, and $\Xi$ to be a matrix with elements $\Xi_{\tilde{k}, i}=\left(\partial \pi_{i} / \partial q^{\tilde{k}}\right)_{\theta}$. Then (19) can be written as

$$
q-1=s \Xi \Lambda^{-1}
$$

Eq. (18) states that with the optimal tax structure, the absolute reduction in the consumption of good $\tilde{k}$ resulting from the optimal tax system is approximately equal to the welfare cost associated with moral hazard from a unit increase in the tax on good $\tilde{k}$. This is analogous to the RamseySamuelson proportional reduction formula. Here, however, lump-sum transfers (the $x$ 's) are allowed.

\subsection{Decentralizability of the constrained optimum}

It is easy to verify that in general (20) implies $q \neq 1$ (this will be apparent from the special cases treated in the next scction). This, in turn, implies that competitive equilibrium without government intervention is not a constrained Pareto optimum.

If the government imposes the set of taxes $\left(q^{*}\right)$ computed according to (20), but lets the market provide insurance, will the resulting competitive equilibrium be efficient? There are two obvious potential problems. First, the social optimum may entail overall losses or profits from insurance; this can be handled by imposing a lump-sum tax on consumers which is equivalent to imposing a per-client tax on insurers. Second, because of non-convexities, firms could, depending on the disequilibrium adjustment mechanism, settle at a local rather than the global optimum. This would not occur if firms competed 'aggressively'. There is another difficulty. Insurance companies ignore the effect of the policies they offer on government tax revenue. They face the minimization problem

$$
\begin{aligned}
& \min _{x} \sum_{i} \pi_{i}\left(q^{*}, x+y\right)\left(x_{i}+y_{i}\right) \\
& \text { s.t. } \\
& \sum_{i} \pi_{i}\left(q^{*}, x+y\right) V_{i}\left(q^{*}, x+y\right)=\overline{\mathrm{E} U},
\end{aligned}
$$


while the dual of the planner's problem is different,

$$
\begin{aligned}
& \min _{x} \sum_{i} \pi_{i}\left(q^{*}, x+y\right)\left(x_{i}+y_{i}-\left(q^{*}-I\right) c_{i}\right) \\
& \text { s.t. } \\
& \sum_{i} \pi_{i}\left(q^{*}, x+y\right) V_{i}\left(q^{*}, x+y\right)=\overline{\mathrm{E} U} .
\end{aligned}
$$

One can react in at least three ways to this non-decentralizability result. First, one may view it as demonstrating that for constrained efficiency, it is necessary not only to have commodity taxation but also to have the government undertake all insurance. Second, one can interpret it as demonstrating that the market can be used to supply insurance efficiently, but the government must provide the firms with a conditional revenue subsidy $R=R(x)=\sum_{i} \pi_{i}\left(q^{*}, x+y\right)\left(q^{*}-1\right) c_{i}\left(q^{*}, x+y\right)$. Third, one may argue that the government is an inefficient provider of insurance or could not properly compute $R(x)$, so that one should set up the planning problem such that the planner has control of $q$, but only indirect control of $x$. We are agnostic concerning the interpretation of the above non-decentralizability result. In any event, it is of interest to ask how the optimal tax formula is altered if, for whatever reason, the government can set only commodity taxes and has only indirect control over insurance companies via taxes.

With private sector provision of insurance, we have a three-tier problem. At the bottom, we have the consumer who chooses effort and consumption, taking consumer prices and the terms of insurance as given. Above we have the insurance companies which choose the terms of insurance, taking consumer prices as given, but taking into account how their clients vary effort in response to changes in the insurance contract. And finally, at the top is the government which sets consumer prices, taking into account how firms will respond, and also how consumers will respond both directly and through induced changes in the insurance contract.

In the two-tier optimal tax problem whcre the government controls both net insurance payouts and tax rates, the optimal tax formulae contain firstand second-order derivatives of the outcome-contingent utility function and the probability of accident function. In the three-tier problem outlined above, the optimal tax formulae would contain first-, second-, and third-order partial derivatives of the utility and probability-of-accident functions. Thus, the determinants of optimal taxes in the three-tier problem are 'an order more complicated' than in the two-tier problem, for example depending on the rate of change of elasticities in addition to elasticities.

We shall not derive the optimal tax formulae for the case where the market provides insurance, and in the rest of the paper shall continue to assume that the government provides insurance. In some contexts, such as 
the optimal taxation of cigarettes when medical care is socialized, this assumption is prima facie reasonable. In other contexts, it may not be; how misleading it is to compute optimal taxes assuming that the government provides insurance when in fact the market does so is an empirical issue.

\section{Some simple cases}

\subsection{Accident-prevention effort and equipment, and separable, outcome- independent utility}

In this subsection we consider an economy in which there is a consumption good, $c$, which does not affect the probability of accident directly, an accident-prevention good, $f$, which does not affect utility directly, and a single kind of effort, $e$, and in which there are only two possible outcomes either a fixed-damage accident occurs or it does not. We assume that the planner has direct control of prices and insurance. Since expected utility is homogeneous of degree zero in consumer prices and income, we are allowed an additional normalization, and assume the consumer price of the consumer good to be unity. (Recall that all producer prices are unity.) And let q, without a subscript, denote the consumer price of the accident-prevention good. Note that, with this normalization, either the accident-prevention good will be taxed and insurance subsidized or vice versa.

We employ the same notation as in the previous section, except that, since we now have only one kind of each commodity, we drop superscripts. We adopt the convention that $y_{0}>y_{1}$. Thus, the size of the fixed-damage accident is $y_{0}-y_{1}$. Finally, we assume that utility is separable and outcomeindependent. Thus, wherc $\pi$ is the probability of accident, expected utility is

$$
\mathrm{E} U=(1-\pi(e, f)) u\left(y_{0}+x_{0}-q f\right)+\pi(e, f) u\left(y_{1}+x_{1}-q f\right)-e,
$$

and the economy's resource constraint is

$$
(1-\pi(e, f)) x_{0}+\pi(e, f) x_{1}-(q-1) f=0 .
$$

Applying (20) to this problem gives: ${ }^{14}$

$$
(q-1)=\left(\frac{\partial \pi}{\partial q}\right)_{\theta}\left(x_{1}-x_{0}\right) /\left(\frac{\partial f}{\partial q}\right)_{\theta} .
$$

Since utility is outcome-independent, the individual receives a larger net payout if the accident occurs than if it does not, i.e. $x_{1}>x_{0}$. Ordinarily,

\footnotetext{
${ }^{14}$ Note that the derivation of $(20)$ did not depend on the normalization employed in the previous section. Thus, $(20)$ is applicable here even though a different normalization is employed.
} 
increasing the price of the accident-prevention good will discourage its purchase and increase the probability of an accident. In this case, the accident-prevention good should be subsidized. It seems plausible, however, that there are situations where the accident-prevention good should be taxed; e.g. driving a safer car may make an individual so much more complacent at the wheel that the probability of accident increases. Let us investigate this possibility further. It can be shown that $(\partial f / \partial q)_{\theta}<0 .{ }^{15}$ Combining this result with $x_{1}>x_{0}$ implies that $q-1$ has the opposite sign to $(\partial \pi / \partial q)_{\theta}$. Now,

$$
\pi_{e}\left(u_{1}-u_{0}\right)-1=0
$$

where $\pi_{e} \equiv(\partial \pi / \partial e)$, etc. and

$$
\pi_{f}\left(u_{1}-u_{0}\right)-q\left((1-\pi) u_{0}^{\prime}+\pi u_{1}^{\prime}\right)=0 .
$$

From total differentiation of $(24 a)$ and $(24 b)$, one obtains that $(\partial \pi / \partial q)_{\theta}$ has the same sign as

$$
\frac{\pi_{f} \pi_{e e}}{\pi_{e}}-\pi_{e f}+q \pi_{e} \frac{u_{1}^{\prime}-u_{0}^{\prime}}{u_{1}-u_{0}}
$$

We know that $\pi_{e}<0, \pi_{f}<0, u_{0}>u_{1}, u_{1}^{\prime}>u_{0}^{\prime}$ (since utility is separable and outcome-independent and only partial insurance is provided) and $\pi_{e e}>0$ [from (24a)]. Thus, the expression in (25) and thereafter $(\partial \pi / \partial q)_{\theta}$ can be negative only if $\pi_{e f}$ is much greater than the zero, i.e. if the accidentprevention good substantially reduces the marginal efficiency of effort $\left(-\pi_{e}\right)$. We say that an accident-prevention good for which this holds is very effortretarding. Note that this property can be consistent with the second-order conditions of the individual's maximization problem.

The sign of $\left[\pi_{f}-\left(\pi_{e f} \pi_{e} / \pi_{e e}\right)\right]$ depends on the 'normality' of accidentprevention equipment in the probability-of-accident function, namely if a decrease in the probability of accident, holding the 'relative price' of effort and accident-prevention equipment fixed, is most efficiently achieved with an increase (decrease) in accident-prevention equipment, then such equipment is normal (inferior). Inferiority is necessary but not sufficient for an accidentprevention good to be very effort-retarding. ${ }^{16}$ Fig. 1 portrays a normal and an inferior accident-prevention good.

We present the result of this subsection in:

\footnotetext{
${ }^{15}$ This follows directly by differentiating the first-order conditions for $e$ and $f$, making the appropriate compensation.

${ }^{16} \mathrm{~A}$ very effort-retarding good is roughly analogous to a Giffen good.
} 


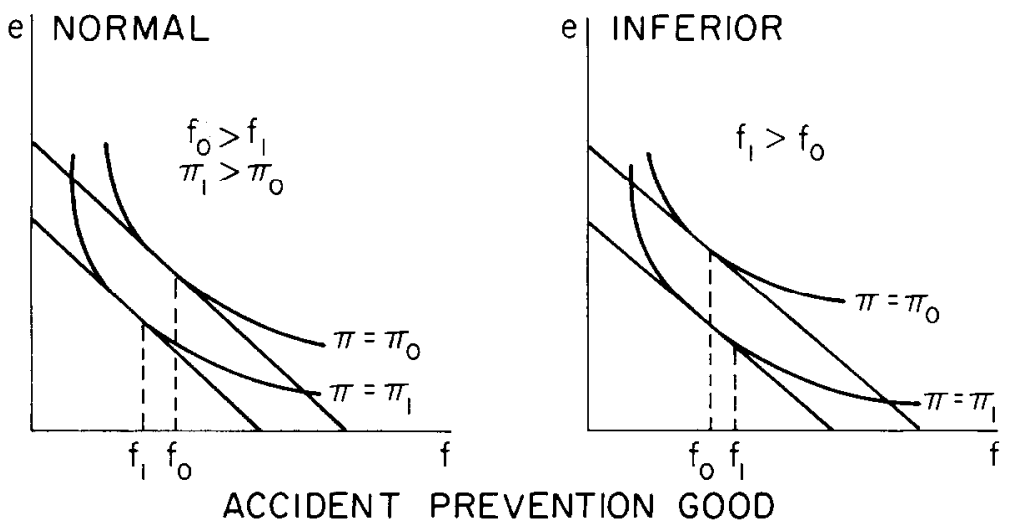

Fig. 1. Normal and inferior accident-prevention goods.

Proposition 2. In the economy treated in this subsection (two outcomes; separable, outcome-independent utility; a single consumer good; a single accident-prevention good which can be taxed linearly; and accidentprevention effort which is untaxable), the accident-prevention good should be taxed if it is very effort-retarding and subsidized otherwise. ${ }^{17}$

\subsection{Accident-prevention effort and more than one consumer good}

The economy to be treated in this subsection is like that of the previous subsection except that instead of one consumer good and one accidentprevention good there are two consumer goods, $a$ and $h$, neither of which affects the probability of an accident. Having set all producer prices equal to unity, we choose good $a$ as the numeraire, and let $q$ denote the consumer price of good $b$. Since $y_{i}+x_{i}=c_{i}^{a}+q c_{i}^{b}$ from the consumer's budget constraint, utility with outcome $i$ is $u_{i}\left[y_{i}+x_{i}-q c_{i}^{b}, c_{i}^{b}, e\right]$. In this case, (20) becomes:

$$
q-1=\frac{\left(\frac{\partial \pi}{\partial q}\right)_{\theta}\left(s_{1}-s_{0}\right)}{(1-\pi)\left(\frac{\partial c_{0}^{b}}{\partial q}\right)_{\theta}+\pi\left(\frac{\partial c_{1}^{b}}{\partial q}\right)_{\theta}}
$$

\footnotetext{
${ }^{17}$ In interpreting the models of this subsection we have treated outcome 0 as 'no accident' and outcome 1 as 'accident'. We could just as well, however, have assumed that an accident always occurs, and that the amount of effort affects the damage caused by the accident. In this case, instead of speaking of accident-prevention goods and effort, one would want to speak of damage-reducing goods and effort. Fire extinguishers and seat belts are two obvious examples of damage-reducing goods. Thus, one wants to subsidize fire extinguishers as long as doing so does not make the individual much more careless.
} 
where $\pi$ is the probability of accident. Assume for the sake of argument that good $b$ is more complementary with effort than good $a$ in the sense that $(\partial \pi / \partial q)_{\theta}>0$ - a rise in the relative price of good $b$ discourages effort. Normally, we expect that $s_{1}>0>s_{0}-$ the net subsidy when the accident occurs is larger than when it does not. In this case, since $\left(\partial c_{0}^{b} / \partial q\right)_{\theta}$ and $\left(\partial c_{1}^{b} / \partial q\right)_{\theta}$ are both negative, $q-1<0$, and good $b$ should be subsidized. This accords with the intuition that one wants to subsidize goods that are complementary to effort.

But (26) also points out that there can be exceptions to this intuition. If the net subsidy is smaller when the accident occurs than when it does not $\left(s_{0}>0>s_{1}\right)$, then goods that are more complementary to effort should be taxed. In this case, the individual expends too much effort at accident prevention, and hence effort should be discouraged. ${ }^{18}$ This case is something of a curiosum, but it can occur when the accident is very marginal-utilitydecreasing $\left(\partial V_{0} / \partial z \gg \partial V_{1} / \partial z\right.$ for all $\left.z\right)$ numbing the victim's capacity to experience pain or pleasure. We summarize this result in:

Proposition 3. In the economy treated in this subsection (two outcomes: two consumer goods which can be taxed linearly; and accident-prevention effort which is untaxable), the consumer good which is more complementary to effort should be subsidized, except if the net social subsidy is higher when the accident does not occur in which case it should be taxed. ${ }^{19}$

\section{Some policy applications}

There are a host of current policy issues to which our analysis is applicable. Indeed, because of the pervasiveness of moral hazard, there is potential scope for government intervention in virtually all markets. In a few markets, however, the distortions caused by the provision of insurance seem sufficiently large that the appropriate ways of ameliorating them merit individual attention.

\footnotetext{
${ }^{18}$ This argument can be formalized as follows. Suppose effort were observable. Then the optimal amount of effort would solve:

$$
\begin{gathered}
\max _{c_{0}^{a}, c_{0}^{b}, c_{1}^{a}, c_{1}^{b}, e} \mathscr{L}=(1-\pi(e)) u_{0}\left(c_{0}^{a}, c_{0}^{b}, e\right)+\pi(e) u_{1}\left(c_{1}^{a}, c_{1}^{b}, e\right) \\
-\lambda\left((1-\pi(e))\left(c_{0}^{a}+c_{0}^{b}-y_{0}\right)+\pi(e)\left(c_{1}^{a}+c_{1}^{b}-y_{1}\right)\right), \\
e:\left\{\pi^{\prime}\left(u_{1}-u_{0}\right)+(1-\pi) \frac{\partial u_{0}}{\partial e}+\pi \frac{\partial u_{1}}{\partial e}\right\}+\left\{\lambda \pi_{e}\left(s_{0}-s_{1}\right)\right\}=0 .
\end{gathered}
$$

In competitive equilibrium with moral hazard, the term in the first curly brackets equals zero. Thus, at the competitive equilibrium, $\partial \mathscr{L} / \partial e=\lambda \pi_{e}\left(s_{0}-s_{1}\right)<0$, so a welfare improvement would be made by decreasing effort.

${ }^{19}$ This intuilive statement of the result is strictly correct only when the consumer good which is less complementary to effort is the numeraire.
} 


\subsection{Automobile accidents}

There is a general consensus that automobile insurance, if it has not significantly increased the probability of an accident occurring, has increased the average size of accident damage.

We have seen that the structure of optimal taxation is complicated by interdependencies between and within the probability-of-outcome and outcome-contingent utility functions. In the discussion which follows, we ignore these complications. Then the optimal tax structure will involve: taxing gasoline ${ }^{20}$ (to encourage people to drive less), taxing alcohol (to encourage people to drive more carefully), imposing penalties on careless driving, subsidizing maintenance, taxing cars, with a higher tax on less safe and more expensive cars, subsidizing coffee breaks (to encourage people to be more alert when driving), and imposing penalties for not wearing seat belts. One might also want to tax complements and subsidize substitutes. This could involve subsidizing alternative modes of transport. Accidents on these alternative modes are insured against, and this insurance too is characterized by moral hazard. But one suspects that, per passenger-mile, the deadweight loss associated with moral hazard is higher for private cars than for other forms of transportation.

The taxation of body repair is a superfluous policy. Any outcome the government can achieve via the taxation (not necessarily linear) of bodywork or, more generally, accident damage repair, it can also achieve by varying payouts. ${ }^{21}$

\subsection{Social security}

Diamond and Mirrlees (1978) consider an economy in which individuals are ex ante identical, but some, as they age, develop disabilities which make early retirement more attractive. The problem faced by the government is how to design social security when it cannot ascertain the extent to which a particular individual is disabled. The more attractive are provisions for early retirement, the more insurance is provided the disabled, but at the same time, the more attractive it becomes for able individuals to retire 'too early'.

The probability distribution of retirement ages is analogous to the probability distribution of accident damages in our model (with earlier retirement corresponding to higher damage). Consumption in different periods is analogous to different goods in our model. Consumption in earlier periods is damage-reducing since it causes the individual to save less, which

\footnotetext{
${ }^{20}$ We have adopted the most intuitive normalization: those goods the level of consumption of which has no effect on the probability of accident have a unit consumer price.

${ }^{21}$ There is another important moral hazard phenomenon in this context. Both the accident victim and the repair company have an incentive to inflate the repair bill (splitting the excess of claimed over aclual repair costs).
} 
makes retiring less attractive; and similarly, consumption in later periods is damage-increasing. Relative to the symmetric information optimum, the provision of social security causes too many people to retire at too early an age. The deadweight loss associated with this can be reduced by subsidizing consumption when young and taxing consumption when old, or more straightforwardly by taxing savings. This discourages saving, which makes an individual less inclined to retire.

One could enrich the Diamond-Mirrlees model to allow for different types of goods. In such an economy one might want to subsidize those goods that encourage later retirement of the able, and tax those that encourage earlier retirement. One might therefore want to subsidize companies' attempts to improve working conditions, and tax goods that are complementary to retirement interests.

\subsection{Medical insurance}

The government should tax those goods and activities that are conducive to ill health, and subsidize those associated with good health. Some such measures are already in effect in most developed countries. The taxation of alcohol and cigarettes is an example, though it is doubtful whether the principal aim of these taxes was the reduction in the deadweight loss from the moral hazard associated with the provision of medical insurance. The subsidization of preventive medical care and light exercise and the taxation of high cholesterol food might be warranted. Non-preventive medical care is analogous to body-work.

\subsection{Sharecropping and other principal-agent problems}

Most economists have a good understanding of what moral hazard is, but it is our feeling that the importance and ubiquity of moral hazard tend to be underestimated. For almost all risks, the probability of accident or the size of damage conditional on the accident occurring is affected by the victim's actions which are only imperfectly observable. As a result, insurance markets against virtually every risk are incomplete or absent. And when an insurance market is incomplete, institutions frequently develop that provide nonmarket insurance, perhaps explicit, perhaps implicit, perhaps formal, perhaps informal. Thus, moral hazard is present not only in insurance markets, but in these numerous social institutions as well.

Besides market insurance, informal insurance, and government-provided insurance, there is another large class of institutions which provide (implicit) insurance-principal-agent relationship. An example which has been extensively discussed is the landlord-tenant contract [Stiglitz (1974), for cxample]. The moral hazard problem is that the provision of implicit 
insurance to the agricultural laborer discourages effort. The deadweight loss associated with this can be reduced by subsidizing complements to effort. Thus, if a happy worker is a good worker, it might benefit the landlord to construct entertainment facilities. And if there is a problem with workers spending too much time at the local café, prices should be raised. Since indebtedness and purchases of inputs may both affect effort, they too should be taxed or subsidized. The attempt to internalize these 'externalities' lcads to interlinkage of land, labor, credit, and commodity markets [Braverman and Stiglitz (1982) and Mitra (1983)]. Other familiar principal-agent relationships are those between employer and employee (the implicit contracts literature), borrower and lender [e.g. Stiglitz and Weiss (1981)], and physician and patient [e.g. Arrow (1965)].

\section{Some comments}

\subsection{Magnitude of welfare loss}

The reader will no doubt have asked himself: (a) how significant is the deadweight loss associated with the various forms of moral hazard we have discussed; (b) what is the approximate magnitude of taxes and subsidies based on thesc considerations; (c) how are the optimal tax and subsidy rates to be computed; and (d) may not the administrative and other costs of imposing a complex system of taxes and subsidies to reduce the deadweight loss associated with moral hazard exceed the benefits? The simple answer is that neither the theoretical nor the empirical work that would be required to answer these questions has been done. Insurance actuaries probably have a good idea of how responsive the probability of a particular accident is to the parameters of the insurance contract. But this datum reflects not only moral hazard, but also adverse selection; as the contract is modified, not only may each client alter his accident-prevention behavior, but also the client population may change. Since the welfare properties of economies with both moral hazard and adverse selection have not yet been investigated, we do not know what actuarial data would be necessary to compute the deadweight loss associated with moral hazard-cum-adverse selection nor how to undertake the computation.

Our intuition is that the deadweight loss due to moral hazard is probably important enough in some contexts, most notably health, theft, fire, automobile accidents, social security, and unemployment insurance, to warrant corrective taxation.

\subsection{Pecuniary externalities matter}

To say that a good should be taxed is equivalent to saying that the shadow price of the good exceeds its market price. This statement has an 
interesting implication. In an economy with moral hazard, pecuniary externalities 'matter'; by 'matter' we mean that government intervention is justified to internalize the externality. In a classic competitive economy, pecuniary externalities do not matter since the social benefit associated with the marginal unit equals the social cost. The purchase of the marginal unit causes prices to change throughout the economy, which induces a string of marginal reallocations. But since the social benefit of each of these marginal reallocations equals the social cost, the pecuniary externality creates no deadweight loss. In an economy with moral hazard, however, since the social benefit of the marginal reallocations is not in general equal to the corresponding social cost, pecuniary externalities alter the aggregate deadweight loss in the economy and thus matter.

\subsection{The invisible hand is clumsy, but so is the government}

The welfare properties of economies with moral hazard are markedly different from those of Arrow-Debreu economies. Notably, the Invisible Hand Theorem fails to hold in economies with moral hazard. Since there are elements of moral hazard in virtually all markets, this suggests a limited domain of applicability of the Fundamental Theorem of Welfare Economics. ${ }^{22}$

In suggesting that there is scope for government intervention, it should be emphasized that we have ignored the costs of government intervention. These may, however, be substantial and exceed any possible efficiency gains from differential commodity taxation. In this case, even though shadow prices deviate from market prices, the market allocation, since it cannot be improved upon, must be said to be constrained efficient. Hence, the market failures we identify should be interpreted as potential market failures, becoming actual market failures only when the benefits of government intervention exceed the costs. ${ }^{23}$

\subsection{Differences between government and private firms}

If firms could observe individual's total purchases, then they could sell

\footnotetext{
${ }^{22}$ See Arnott and Stiglitz (1984b) for a more extensive discussion of the welfare economics of moral hazard.

${ }^{23}$ The traditional welfare theorems assert that no government intervention could improve upon the market allocation; since not even an 'ideal' government could do better than the market, one did not need to model precisely the 'imperfect' governments. Our contention here is that the market fails this stringent test; an ideal government could effect improvements. But to fail the more relevant test, of whether actual government intervention would likely improve welfare necessitates modelling the costs of government intervention and government behavior. Thus, constrained efficiency should be defined not only contingent on the information acquisition technology, or more restrictively on what information is and is not available to whom, but also treating market structure as endogenous and taking into account the technology of government intervention.
} 
total packages to individuals, tieing their purchases of commodities and insurance. In this case, government intervention would be unnecessary since there is no allocation the government could achieve which firms could not also.

If, however, an individual's total purchases of commodities are not observable, then even when the government has no informational advantage over firms, it can improve on the market equilibrium. Competitive firms have no choice but to price goods at cost; any firm which tried to do what the tax system does, pricing some goods above cost and subsidizing others, would make a loss since individuals would purchase the subsidized goods but not the others. The government, however, through its coercive powers of taxation is able to drive a wedge between producer and consumer prices.

\section{Conclusions}

In this paper we have made a simple yet, we believe, important point: in competitive equilibrium (with no government intervention) in an economy with asymmetric information, shadow prices will generally deviate from market prices. There is a welfare loss associated with the informational asymmetries, the size of which depends on individuals' consumption patterns. If increased consumption of a good reduces this welfare loss, the good should be subsidized whenever the reduction in welfare loss exceeds the costs of government intervention.

We investigated a particular case of this general proposition. ${ }^{24} \mathrm{We}$ considered an economy with identical individuals, in which the presence of asymmetric information gave rise to moral hazard. And we considered the determinants of the optimal tax structure in such an economy. Broadly speaking, our results accorded with intuition. The moral hazard arising from the provision of insurance usually causes people to self-protect too little, so those goods whose consumption encourage an individual to self-protect more/less should be subsidized/taxed. Thus, fire extinguishers should be subsidized if having a fire extinguisher reduces accident damage, while alcohol should be taxed if its consumption causes individuals to drive more recklessly. Some of our results, however, are not immediately obvious. First, we demonstrated that there are circumstances, albeit improbable, in which accident-prevention goods and consumer goods that are complementary to accident-prevention effort should be taxed. Second, we showed that as in the optimal commodity tax problem, the determination of the optimal tax structure is far from straightforward. And third, the structure of optimal taxes depends on whether insurance is provided by the government or the market.

\footnotetext{
(1982).

${ }^{24}$ The general proposition itself is examined in greater generality in Greenwald and Stiglitz
} 
There are three obviously worthwhile extensions to our analysis. We treated information as if it were either costless or infinitely costly to acquire; as a result, something was either perfectly observable or unobservable. One would like to treat explicitly the costs of acquiring insurance-relevant information, ${ }^{25}$ particularly since one could then determine the circumstances under which such information acquisition should be subsidized. The analysis should also be extended to treat adverse selection and moral hazard simultaneously. Not only would this alter the optimal tax structure in interesting ways, but also the development of such a model is a necessary condition for both sound, qualitative policy advice, and for the empirical estimation necessary to compute optimal tax rates. Finally, we derived optimal tax formulae for the situation where the government provides insurancc. It would be uscful, but difficult, to perform the same exercise when the market rather than the government provides insurance.

The belief that an unregulated market (and spontaneous non-market institutions) provides many forms of insurance in an inefficient manner is widespread, at least among policy makers and the lay public, and has given rise to extensive government intervention vis-à-vis insurance. This paper and Arnott and Stiglitz (1984b) have provided a theoretical basis for this belief, and have indicated at least some of the factors that should be considered in determining appropriate corrective action by the government.

\section{Appendix A: Derivation of eqs. (17) and (18)}

From $\left(13^{\prime}\right)$ :

$$
\frac{\partial \mathscr{L}}{\partial x_{m}}=\frac{\partial \mathrm{E} U}{\partial x_{m}}-\lambda\left(\sum_{i}\left(\frac{\partial \pi_{i}}{\partial x_{m}} s_{i}+\pi_{i} \frac{\partial s_{i}}{\partial x_{m}}\right)\right)=0 .
$$

Thus using (10):

$$
\sum_{m} c_{m}^{\tilde{k}} \frac{\partial \mathscr{L}}{\partial x_{m}}=\sum_{m} c_{m}^{\tilde{k}} \pi_{m} \alpha_{m}-\lambda\left(\sum_{m} c_{m}^{\tilde{k}} \sum_{i}\left(\frac{\partial \pi_{i}}{\partial x_{m}} s_{i}+\pi_{i} \frac{\partial s_{i}}{\partial x_{m}}\right)\right)=0
$$

Also,

$$
\frac{\partial \mathscr{L}}{\partial q^{\tilde{k}}}=\frac{\partial \mathrm{E} U}{\partial q^{\tilde{k}}}-\lambda\left(\sum_{i}\left(\frac{\partial \pi_{i}}{\partial q^{\tilde{k}}} s_{i}+\pi_{i} \frac{\partial s_{i}}{\partial q^{\tilde{k}}}\right)\right)=0
$$

\footnotetext{
${ }^{25}$ The collection of information has been studied by Holmström (1979) and Shavell (1979a) but for simple economies with moral hazard in which competitive equilibrium is constrained efficient.

The transmission of information, in particular whether firms have an incentive to share information on their common clicnts is the focus of Iellwig (1982).
} 
Using (11) and adding (ii) and (iii) gives:

$$
\sum_{m} c_{m}^{\bar{k}} \sum_{i}\left(\frac{\partial \pi_{i}}{\partial x_{m}} s_{i}+\pi_{i} \frac{\partial s_{i}}{\partial x_{m}}\right)+\sum_{i}\left(\frac{\partial \pi_{i}}{\partial q^{\tilde{k}}} s_{i}+\pi_{i} \frac{\partial s_{i}}{\partial q^{\tilde{k}}}\right)=0 .
$$

From (14):

$$
\sum_{i} \pi_{i} \frac{\partial s_{i}}{\partial x_{m}}=\pi_{m}-\sum_{i} \pi_{i}(q-1) \frac{\partial c_{i}}{\partial x_{m}}
$$

and

$$
\sum_{i} \pi_{i} \frac{\partial s_{i}}{\partial q^{\tilde{k}}}=-\sum_{i} \pi_{i} c_{i}^{\tilde{k}}-\sum_{i} \pi_{i}(q-1) \frac{\partial c_{i}}{\partial q^{\bar{k}}}
$$

Substituting (va) and (vb) into (iv) gives:

$$
\sum_{i}\left(\frac{\partial \pi_{i}}{\partial q^{\tilde{k}}}+\sum_{m} c_{m}^{\tilde{k}} \frac{\partial \pi_{i}}{\partial x_{m}}\right) s_{i}=\sum_{i} \pi_{i}(q-I)\left(\frac{\partial c_{i}}{\partial q^{\tilde{k}}}+\sum_{m} c_{m}^{\tilde{k}} \frac{\partial c_{i}}{\partial x_{m}}\right)
$$

Now define:

$$
\left(\frac{\partial c_{i}^{k}}{\partial q^{\tilde{k}}}\right)_{\theta}=\frac{\partial c_{i}^{k}}{\partial q^{\tilde{k}}}+\sum_{m} c_{m}^{\tilde{k}} \frac{\partial c_{i}^{k}}{\partial x_{m}}
$$

and

$$
\left(\frac{\partial \pi_{i}}{\partial q^{\tilde{k}}}\right)_{\theta}=\frac{\partial \pi_{i}}{\partial q^{\tilde{k}}}+\sum_{m} c_{m}^{\tilde{k}} \frac{\partial \pi_{i}}{\partial x_{m}}
$$

Substituting (viia) and (viib) into (vi) gives:

$$
\sum_{i}\left(\frac{\partial \pi_{i}}{\partial q^{\tilde{k}}}\right)_{\theta} s_{i}=\sum_{i} \pi_{i} \sum_{k}\left(q^{k}-1\right)\left(\frac{\partial c_{i}^{k}}{\partial q^{\tilde{k}}}\right)_{\theta}
$$

Now define the outcome-contingent expenditure function $\mathrm{E}_{i}=\mathrm{E}_{i}\left(q ; \bar{V}_{i}\right)$, and the fixed-probability expenditure function $\mathrm{E}\left(q ; \bar{\pi}_{i}, \bar{V}_{i}\right) \equiv \sum_{i} \bar{\pi}_{i} \mathrm{E}_{i}\left(q ; \bar{V}_{i}\right)$. Then

$$
\sum_{i} \bar{\pi}_{i}\left(\frac{\partial c_{i}^{\tilde{k}}}{\partial q^{k}}\right)_{\theta}=\frac{\partial^{2} \mathrm{E}}{\partial q^{\tilde{k}} \partial q^{k}}=\frac{\partial^{2} \mathrm{E}}{\partial q^{k} \partial q^{\tilde{k}}}=\sum_{i} \bar{\pi}_{i}\left(\frac{\partial c_{i}^{k}}{\partial q^{\tilde{k}}}\right)_{\theta}
$$

Applying (ix) to (viii) gives:

$$
\sum_{i}\left(\frac{\partial \pi_{i}}{\partial q^{\tilde{k}}}\right)_{\theta} s_{i}-\sum_{i} \pi_{i} \sum_{k}\left(q^{k}-1\right)\left(\frac{\partial c_{i}^{\tilde{k}}}{\partial q^{k}}\right)_{\theta}
$$




\section{Appendix B}

In this appendix we treat an economy in which there is a single accidentprevention good $f$ which enters the accident-probability function but not the utility function, and a single consumer good which enters the utility function but not the accident-probability function, and no accident-prevention effort. Though this case is of little practical relevance since there is always some unobservable accident-affecting activity, it has some peculiar characteristics worth noting. Where an accident is defined as being relatively-utilitydecreasing or relatively-utility-increasing according to whether $u_{0}>u_{1}$ or $u_{0}<u_{1}$ whenever $\partial u_{0} / \partial y_{0}=\partial u_{1} / \partial y_{0}$, we obtain: ${ }^{26}$

(i) if the accident is relatively-utility-decreasing, the symmetric information optimum can be achieved by the government;

(ii) if utility is outcome-independent, the symmetric information optimum can almost (arbitrarily closely) be achieved by the government providing the accident-prevention good at an arbitrarily low but positive price: and

(iii) if the accident is relatively-utility-increasing, the symmetric information optimum cannot normally be achieved. The asymmetric information optimum is achieved by the government providing the accident-prevention good at an arbitrarily low price.

The symmetric information optimum, in which the planner can directly control the individual's purchases, is the solution to

$$
\begin{aligned}
& \max _{f, c_{1}, c_{0}}(1-\pi(f)) u_{0}\left(c_{0}\right)+\pi(f) u_{1}\left(c_{1}\right) \\
& \text { s.t. } \\
& \text { (i) } \quad(1-\pi(f)) c_{0}+\pi(f) c_{1}+\dot{f}=(1-\pi(f)) y_{0}+\pi(f) y_{1} \text {, }
\end{aligned}
$$

and is characterized by the resource constraint (B1.i),

$$
u_{0}^{\prime}=u_{1}^{\prime}=u^{\prime}
$$

and

$$
\pi_{f}\left(\left(u_{1}-u_{0}\right)-u^{\prime}\left(\left(c_{1}-y_{1}\right)-\left(c_{0}-y_{0}\right)\right)\right)=u^{\prime}
$$

We now examine the asymmetric information optimum in which the planner can only indirectly influence the individual's purchases of $c$ and $f$ by

\footnotetext{
${ }^{26}$ We say that an accident is absolutely-utility-decreasing or simply utility-decreasing if $u_{0}(\Phi)>u_{1}(\Phi)$, for all $\Phi>0$ and marginal-utility-decreasing if $u_{0}^{\prime}(\Phi)>u_{1}^{\prime}(\Phi)$ for all $\Phi>0$

The assumption that an accident is relatively-utility-decreasing implies, for instance, that an individual who has a limb severed and has it replaced by an artificial limb, and is compensated to the point where his marginal utility of income is the same as if his limb had not heen severed, would still have preferred not to have the limb severed.
} 
setting $x_{0}, x_{1}$, and $q$. The consumer good is numeraire. We first treat the case of:

(i) Relatively-utility-decreasing accidents. Eq. (20) reduces to

$$
q-1=\pi_{f}\left(x_{1}-x_{0}\right)
$$

The equation characterizing the individual's choice of how many units of the accident-prevention good to buy is

$$
\pi_{f}\left(u_{1}-u_{0}\right)-q\left(\pi u_{1}^{\prime}+(1-\pi) u_{0}^{\prime}\right)=0
$$

The resource constraint is

$$
(q-1) f=(1-\pi(f)) x_{0}+\pi(f) x_{1} \text {. }
$$

If one solves for the optimal values of $x_{0}$ and $x_{1}$, one obtains:

$$
u_{0}^{\prime}=u_{1}^{\prime}
$$

Let $*$ denote values of variables at the symmetric information optimum. It may be checked that if the government sets

$$
q^{*}=\frac{\left(u_{1}^{*}-u_{0}^{*}\right) \pi_{f}^{*}}{\left(u^{\prime}\right)^{*}}=\pi_{f}^{*}\left(x_{1}^{*}-x_{0}^{*}\right)+1
$$

[from (B.3), (B.4) and (B.6)], $x_{0}=x_{0}^{*}$ and $x_{1}=x_{1}^{*}$, then the individual will choose $f^{*}$, and the symmetric information optimum will be attained.

Upon reflection, this result is not surprising. Competitive equilibrium without government intervention fails to achieve the symmetric information optimum only because individuals, if they were provided with full insurance, would purchase an inefficient quantity of accident-prevention goods. This can be remedied directly by subsidizing or taxing these goods. If, with full insurance, the individual has an incentive both to purchase and to use the accident-prevention goods, then the government can achieve the symmetric information optimum by providing full insurance and adjusting the price of the accident-prevention goods so that the individual purchases the optimal amount. Accident-prevention effort, however, is different. Since it is untaxable, one can stimulate it only indirectly, by taxing substitutes and subsidizing complements, which causes an efficiency loss relative to the symmetric information optimum.

When the accident is relatively-utility-decreasing, the accident-prevention good will typically be subsidized. There is one circumstance in which the accident-prevention good should be taxed - if the accident is so relatively- 
utility-decreasing that when $u_{0}^{\prime}=u_{1}^{\prime}, x_{0}>x_{1}$; this case was explained in scction 3.2 of the text.

(ii) Relatively-utility-increasing accidents. In deriving the optimal tax formula, it was assumed that if an individual purchases a good, he will use it. With relatively-utility-increasing accidents, application of the optimal tax formulae gives that full insurance is provided and $q=\left(u_{1}^{*}-u_{0}^{*}\right) \pi_{f}^{*} /\left(u^{\prime}\right)^{*}$, which is negative. The individual is better off if the accident occurs and to encourage him to purchase the accident-prevention good, it is necessary to set its price negative. This solution is satisfactory if the government can both monitor and enforce an individual's use of the good. ${ }^{27}$ In many contexts, however, the costs of doing so would be prohibitive. Faced with a negative price, individuals would then buy as many units of the good as possible, since doing so, with a negative price, would increase income, but would not use them since utility is higher when an accident occurs. Thus, with relatively-utility-increasing accidents, the symmetric information optimum may not be attainable. If the government is unable to enforce usage, then to give individuals the incentive to employ accident-prevention goods, it is necessary that $u_{0}>u_{1}$. In this case, the asymmetric information optimum is the solution to

$$
\begin{aligned}
& \max _{f, c_{1}, c_{0}}(1-\pi(f)) u_{0}\left(c_{0}\right)+\pi(f) u_{1}\left(c_{1}\right) \\
& \text { s.t. } \\
& \text { (i) } \quad(1-\pi(f)) c_{0}+\pi(f) c_{1}+f=(1-\pi(f)) y_{0}+\pi(f) y_{1} \text {, } \\
& \text { (ii) } u_{0}=u_{1}+\Delta,
\end{aligned}
$$

where $\Delta$ is an arbitrarily small, positive number. Denote the solution to this problem by $\tilde{f}, \tilde{c}_{1}$, and $\tilde{c}_{0}$. The government can attain this optimum by setting the price of the accident-prevention good equal to

$$
\varepsilon=-\frac{\pi_{f}(\tilde{f}) \Delta}{\pi(\tilde{f}) u_{1}^{\prime}\left(\tilde{c}_{1}\right)+(1-\pi(\tilde{f})) u_{0}^{\prime}\left(\tilde{c}_{0}\right)}
$$

(iii) Outcome-independent utility functions. The reader can check that in, this case the planner can come arbitrarily close to the symmetric social welfare optimum by setting $u_{0}^{*}=u_{1}^{*}+\theta$, where $\theta$ is an arbitrarily small positive number and then $q=\theta \pi_{f}^{*} /\left(u^{\prime}\right)^{*}$.

\footnotetext{
${ }^{27}$ With enforcement costs, the most efficient method of compulsion would be to apply an infinitely large fine for non-compliance and to inspect for non-compliance with an infinitesmal but strictly positive probability.
} 


\section{References}

Arnott, R.J. and J.E. Stiglitz, 1984a, Basic analytics of moral hazard, Mimeo.

Arnott, R.J. and J.E. Stiglitz, 1984b, Equilibrium in competitive insurance markets: The welfare economics of moral hazard, part III, Some welfare implications of the analysis, Mimeo.

Arrow, K., 1965, Aspects of the theory of risk-bearing (Yrjö Jahnssonin Säätiö, Helsinki).

Atkinson, A.B. and J.E. Stiglitz, 1980, Lectures on public economics (McGraw-Hill, New York).

Braverman, A. and J.E. Stiglitz, 1982, Sharecropping and the interlinking of agrarian markets, American Economic Review 72, 695-715.

Diamond, P.A. and J.A. Mirrlees, 1978, A model of social insurance with variable retirement, Journal of Public Economics 10, 295-336.

Grecnwald, B. and J.E. Stiglitz, 1982, The welfare economics of imperfect information and incomplete markets, Bell Labs., Mimeo.

Hellwig, M., 1982, Moral hazard and monopolistically competitive insurance markets, Mimeo.

Helpman, E. and J.-J. Laffont, 1975, On moral hazard in general equilibrium, Journal of Economic Theory 10, 8-23.

Holström, B., 1979, Moral harard and observability, Bell Journal of Economics 10, 74-91.

Marshall, J.M., 1976, Moral hazard, American Economic Review 66, 880-890.

Mitra, P., 1983, A theory of interlinked rural transactions, Journal of Public Economics 20, 167192.

Pauly, M., 1974, Overprovision and public provision of insurance, Quarterly Journal of Economics 88, 44-62.

Shavell, S., 1979a, On moral hazard and insurance, Quarterly Journal of Economics 93, 541-562.

Shavell, S., 1979b, Risk sharing and incentives in the principal and agent relationship, Bell Journal of Economics 10, 55-73.

Stiglitz, J.E., 1974, Incentives and risk sharing in sharecropping, Review of Economic Studies, 219-255.

Stiglitz, J.E. and A. Weiss, 1981, Credit rationing in markets with imperfect information, American Economic Review 71, 393-410. 